Journal of Machine Engineering, 2020, Vol. 20, No. 4, 99-115

ISSN 1895-7595 (Print) ISSN 2391-8071 (Online)

Received: 10 October 2020 / Accepted: 11 November 2020 / Published online: 29 November 2020

fractals, brushing, roughness parameters

\author{
Pawel KAROLCZAK ${ }^{*}$ \\ Maciej KOWALSKI ${ }^{1}$ \\ Katarzyna RASZKA ${ }^{1}$
}

\title{
THE APPLICATION OF FRACTAL ANALYSIS TO THE DESCRIPTION OF BRUSHED STEEL SURFACES
}

\begin{abstract}
The notion of fractals and the possibility of exploiting them in surface engineering are discussed. The fractal dimension problem is addressed and basic information relating to brushing and roughness parameters is provided. The results of tests on specimens in the form of structural steel ( $2275 \mathrm{JO}$ ) plates subjected to brushing are presented. The machining was conducted using an FWD 32J milling machine with a GE 950 G PLUS straight grinder together with an A11-CB15M brush mounted on it. On the basis of the test results an analysis of selected roughness parameters, with the focus on the different degrees of correlation between the particular indicators and the fractal dimension, was carried out.
\end{abstract}

\section{INTRODUCTION}

The shape of the geometric structure of the working surface is extremely important for the operation of machines and equipment. The depth, density and lay of tool marks determine the surface's performance. The surface can be fully described through its profilometry and spatial parameters. The parameters characterize the features of the measured surface, differing from the actual surface in the error due to the accuracy of the measuring method. The basic tools used for such measurements are profilometers. This measuring method belongs to contact methods exploiting the movement a diamond tool on the machined surface. The main drawback of such methods is their limited accuracy of surface structure mapping due to the size of the measuring needle's radius. Nevertheless, they are characterized by a short measurement time and a wide measuring range and can be applied to surfaces of various types. The profiles obtained in this way can be described by several parameters. Depending on their defining direction the parameters are divided into the three main groups: height parameters, distance parameters and mixed (hybrid)

\footnotetext{
${ }^{1}$ Department of Machine Tools and Mechanical Engineering Technologies, Wroclaw University of Science and Technology, Poland

* E-mail: pawel.karolczak@pwr.edu.pl https://doi.org/10.36897/jme/130618
} 
parameters. The respective parameters characterize surface roughness from different perspectives. This means that one cannot obtain a complete picture of surface structure complexity using only one of the indices. The most often used indices: $R a-$ the arithmetic mean of profile ordinates and $R z$ - the largest profile height provide only limited averaged information. For this reason additional methods of examining and describing the surface are used. One of these methods is fractal analysis [1].

Fractals are sets having a nontrivial structure on every scale. By definition, sets whose topological dimension is smaller (different) than the Hausdorff dimension are referred to as fractals. They are characterized by self-similarity, are difficult to describe through the classic Euclidean space and their appearance can be mostly described as "swirly" or "jagged". Stochastic fractals (having random features) and nonstochastic (deterministic) fractals, formed as a result of successive iterations of functions (algebraic fractals) or shapes (geometric fractals), are distinguished [2].

When talking about fractals, one should mention the notion of fractal dimension - a major numerical characteristic of fractals. The fractal dimension is defined as the minimum number of independent parameters needed to describe a selected set. For example, the fractal dimension for a line, a surface and an area amounts to one, two and three, respectively. There are also other (special) kinds of dimensions from among which the selfsimilarity dimension, the divider dimension and the box dimension are used in fractal analysis [3].

The self-similarity dimension indicates to what degree a part of an object resembles the whole object. Thus a self-similar object is an object which when arbitrarily scaled up will consist of elements similar to the whole. The self-probability dimension can be described by the formula:

$$
a=\frac{1}{S^{D_{S}}}
$$

where: $a$ - the number of scaled down parts, $s-$ a scale-down (reduction) coefficient, $D_{s}$-the self-similarity dimension.

Transforming this formula one gets the following equivalent relation:

$$
D_{s}=\frac{\log a}{\log \frac{1}{s}}
$$

Selected self-similarity dimensions of typical fractals are presented in Table 1.

Table 1. Self-similarity dimensions of various fractal objects [4]

\begin{tabular}{|l|c|c|c|}
\hline Object & Parts $a$ & Scale $s$ & Dimension $D$ \\
\hline Koch curve & $4^{\mathrm{k}}$ & $1 / 3^{\mathrm{k}}$ & $\log 4 / \log 3 \approx 1.2619$ \\
\hline Cantor set & $2^{\mathrm{k}}$ & $1 / 3^{\mathrm{k}}$ & $\log 2 / \log 3 \approx 0.6309$ \\
\hline Sierpinski triangle & $3^{\mathrm{k}}$ & $1 / 2^{\mathrm{k}}$ & $\log 3 / \log 2 \approx 1.5850$ \\
\hline
\end{tabular}


The divider dimension is applied to objects which do not exhibit close similarity or are not self-similar, but to which we want to assign a fractal dimension. The divider dimension is defined by the formula:

$$
D_{c}=1+d
$$

where: $D_{c}$ - the divider dimension, $d$ - the slope of the graph of measured length $u$ logarithms, dependent on measuring accuracy $1 / s$.

The above can be expressed in the following equivalent form:

$$
D_{c}=1+\frac{\log \left(N\left(S_{n+1}\right)\right)-\log \left(N\left(S_{n}\right)\right)}{\log \left(\frac{1}{S_{n+1}}\right)-\log \left(\frac{1}{S_{n}}\right)}
$$

where: $S_{n}$ - the divider opening width, $N\left(S_{n}\right)$ - the number of steps needed to cover a full circumvention at the given divider opening, $S_{n+1}$ - a new, smaller divider opening width, $N\left(S_{n+1}\right)$ - the number of steps at the new divider opening width.

In this method the measurement accuracy to a large degree depends on the divider opening width. The smaller the opening width, the higher the measurement accuracy. Figure 1 and Table 2 show how the length of Great Britain's shoreline changes depending on the adopted divider opening width.

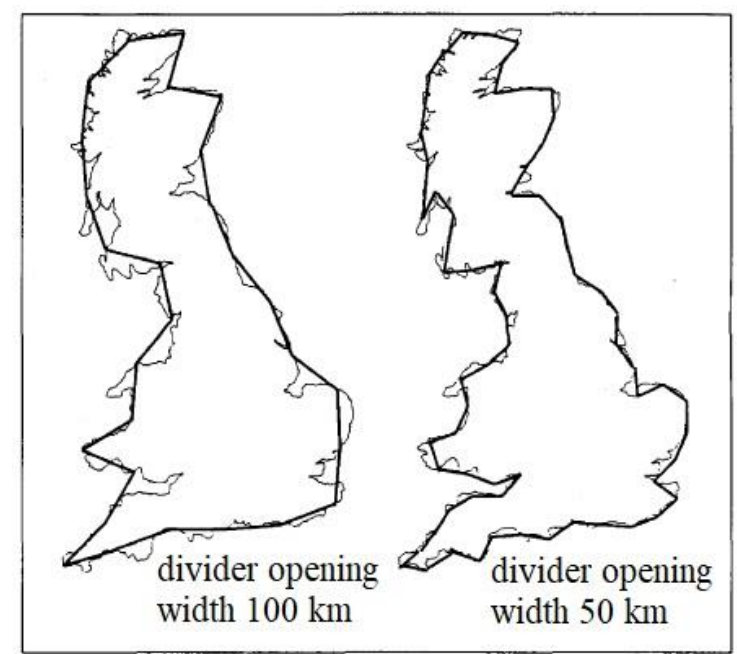

Fig. 1. Approximation of Great Britain's shore using divider method [4]

Table 2. Effect of divider opening width on accuracy of measurement results [4]

\begin{tabular}{|c|c|}
\hline Divider opening width $[\mathrm{km}]$ & Shore length $[\mathrm{km}]$ \\
\hline 500 & 2600 \\
\hline 100 & 3800 \\
\hline 54 & 5770 \\
\hline 17 & 8640 \\
\hline
\end{tabular}


Another dimension commonly used in fractal analysis is the box dimension. It is characterized by the greatest universality - the investigated objects do not have to be selfsimilar or measurable by means of a divider. Measurements can be performed for both planes and three-dimensional spaces. The idea of this method is simple and consists in superimposing a regular grid with constant-size components on the measured structure. Depending on the investigative dimension (2D/3D), the components assume the form of squares or cubes - "boxes" of constant size $s$. Then it is counted in how many of the components the measured structure $N(s)$ occurs. This process is repeated for a smaller size $s$ and a log-log graph is plotted. The box dimension is expressed by the inclination of the straight line in the graph and can be calculated from the formula:

$$
D_{p}=\frac{\log \left(N\left(S_{n+1}\right)\right)-\log \left(N\left(S_{n}\right)\right)}{\log \left(\frac{1}{S_{n+1}}\right)-\log \left(\frac{1}{S_{n}}\right)}
$$

Since the degree of irregularity of a surface can be determined through fractal analysis the latter is often used as an additional tool to describe the condition of a surface [4]. Fractal analysis can be used to describe machinability indices, cutting forces and the surface roughness of difficult-to-machine materials after conventional machining, such as turning [5, 6] and milling [7], abrasive machining [8] and hybrid machining [9, 10].

As an advanced tool for describing the condition of a surface fractal analysis is combined with other unconventional methods, such as wavelet analysis [11] and artificial neural networks [12].

\section{BRUSHING}

Brushing belongs to finishing processes, but unlike most of the popular finishing processes (e.g. grinding, deburring and polishing), it needs not to be conducted on a separate machining station. Usually the aim of brushing is to improve the quality of a surface after profiling and to remove burrs, impurities, corrosion and undesirable coatings. Brushing is considered to be an efficient process easily lending itself to automation owing to the good adjustment of the fibres to the shape of the surface being machined. Brushing includes the features of machining (the fibres' ends work as cutting edges), grinding and burnishing. The forces in this process are evenly distributed on the whole surface being brushed and the resulting surface is similar to that subjected to abrasive machining. Brushing can be applied to both flat surfaces and holes.

The brush itself can be small and depending on the model and the adopted machining parameters it can ensure surface roughness $R a=0.1 \mathrm{um}$. A major characteristic of brushes is the material of which they are made. Brass, steel, nylon and ceramic fibres are used for this purpose [13]. Ceramic brushes, which unlike the other types mentioned above, do not undergo permanent deformation, deserve special mention. Fibres made of $\mathrm{Al}_{2} \mathrm{O}_{3}$ ceramics were used in the present research. 
Changes in the fractal dimension were investigated on three $150 \times 100 \times 1 \mathrm{~mm}$ steel $($ S275JO) specimens. Six brushing operations, performed at variable machining parameters, were carried out on each of the specimens, whereby 18 different surface structures were obtained. The specimens were fixed in a vice in an FWD 32J milling machine. Dry brushing was conducted using an XEBEC TECHNOLOGY A11-CB15M brush (Fig. 2, Table 3) combined with a GE950 G PLUS grinder.

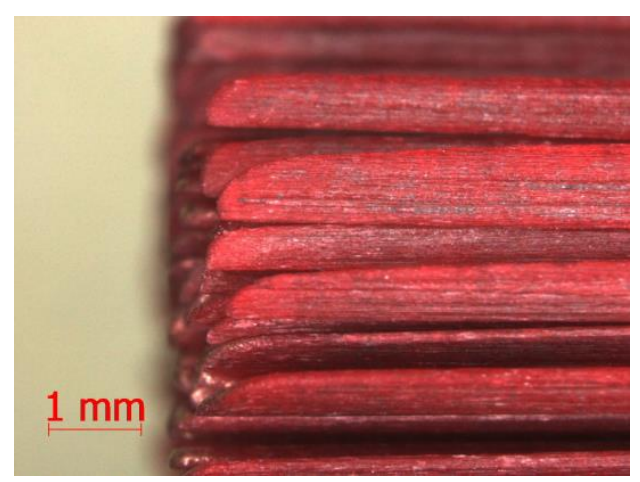

Fig. 2. Brush profile image under $\times 20$ magnification

Table 3. Specifications of brush GE950 G PLUS

\begin{tabular}{|c|c|c|c|c|c|c|c|c|}
\hline \multirow{2}{*}{$\begin{array}{c}\text { Tool } \\
\text { diameter } \\
{[\mathrm{mm}]}\end{array}$} & \multirow{2}{*}{$\begin{array}{c}\text { Fibre } \\
\text { length } \\
{[\mathrm{mm}]}\end{array}$} & \multirow{2}{*}{$\begin{array}{c}\text { Overall } \\
\text { tool } \\
\text { length } \\
{[\mathrm{mm}]}\end{array}$} & \multirow{2}{*}{$\begin{array}{c}\text { Collet } \\
\text { diameter } \\
{[\mathrm{mm}]}\end{array}$} & \multicolumn{2}{|c|}{ Cutting depth [mm] } & \multirow{2}{*}{$\begin{array}{l}\text { Rotational } \\
\text { speed }[\mathrm{rpm}]\end{array}$} & \multirow{2}{*}{$\begin{array}{l}\text { Feed rate } \\
{[\mathrm{mm} / \mathrm{min}]}\end{array}$} & \multirow{2}{*}{$\begin{array}{c}\text { Brush } \\
\text { protrusion } \\
{[\mathrm{mm}]}\end{array}$} \\
\hline & & & & $\begin{array}{l}\text { Vertical } \\
\text { burrs }\end{array}$ & $\begin{array}{c}\text { Horizontal } \\
\text { burrs }\end{array}$ & & & \\
\hline 15 & 50 & 90 & 18.5 & 0.5 & 1.0 & $4800(\max 6000)$ & 1200 & 10 \\
\hline
\end{tabular}

\section{MEASUREMENTS}

For the brushing of the eighteen surfaces the following three variables were distinguished: rotational speed, feed rate and number of tool passes. Tests were carried out for 3 different rotational speeds: 2500, 4000 and $5500 \mathrm{rpm}$ and for each of them surfaces with one and two tool passes were distinguished. Moreover, three different feed rates: 450, 550 and $710 \mathrm{~mm} / \mathrm{min}$ were used in each of the situations.

The measurements were made on a Mitutoyo Surftest SV 3200 roughness measuring machine. The measuring length amounted to $4.8 \mathrm{~mm}$ for $2 \mathrm{D}$ measurement and $1.28 \mathrm{~mm}$ for $3 \mathrm{D}$. The length of the elementary sections $\lambda c$ in both cases was $0.25 \mathrm{~mm}$. In both cases, a measuring needle with a tip rounding radius of $2 \mu \mathrm{m}$ and apex opening angle of $60^{\circ}$ was used. Selected surface profiles and surfaces 3D are presented (Figs 3, 4 and 5) and briefly described below.

Structures whose height is approximately around the mean line level and whose valleys are small predominate in the first profile in Fig. 3. In a few places deep and very deep sharply tipped asperities, resulting from brushing, occur. When the feed rate was increased, more valleys of similar width and height occurred in the next profile. 
The extremely deep valleys and the small raggedness occurring at $v f=450 \mathrm{~mm} / \mathrm{min}$ disappeared. Also an almost flat segment with no visible tool action occurred. When the feed rate was further increased, the profile's fraction of small raggedness expanded, leaving only some medium deep asperities. The width of valleys increased in a few places.

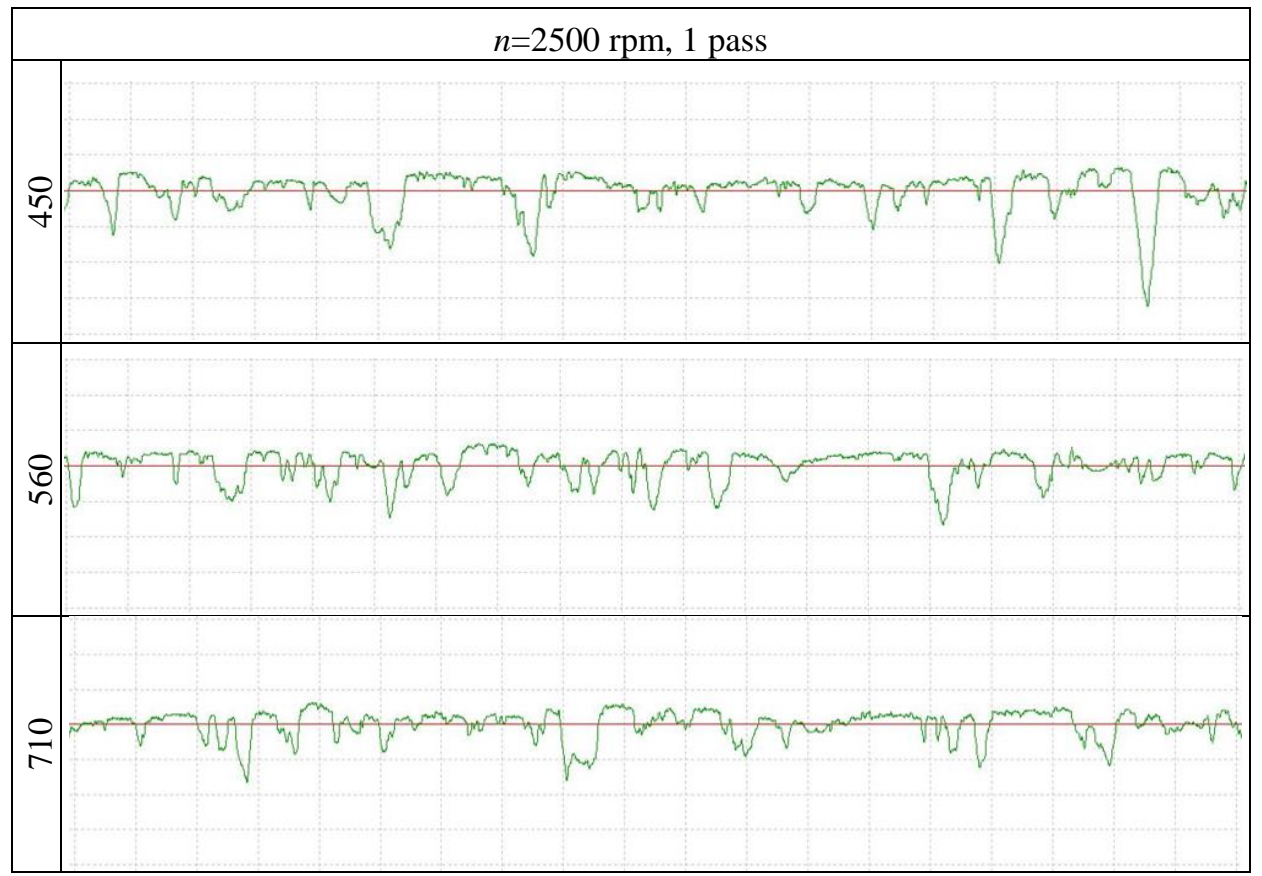

Fig. 3. Profiles of surfaces obtained by brushing at single tool pass, constant rotational speed $n=2500 \mathrm{rpm}$ and variable feed rates $v f=450,560$ and $710 \mathrm{~mm} / \mathrm{min}$

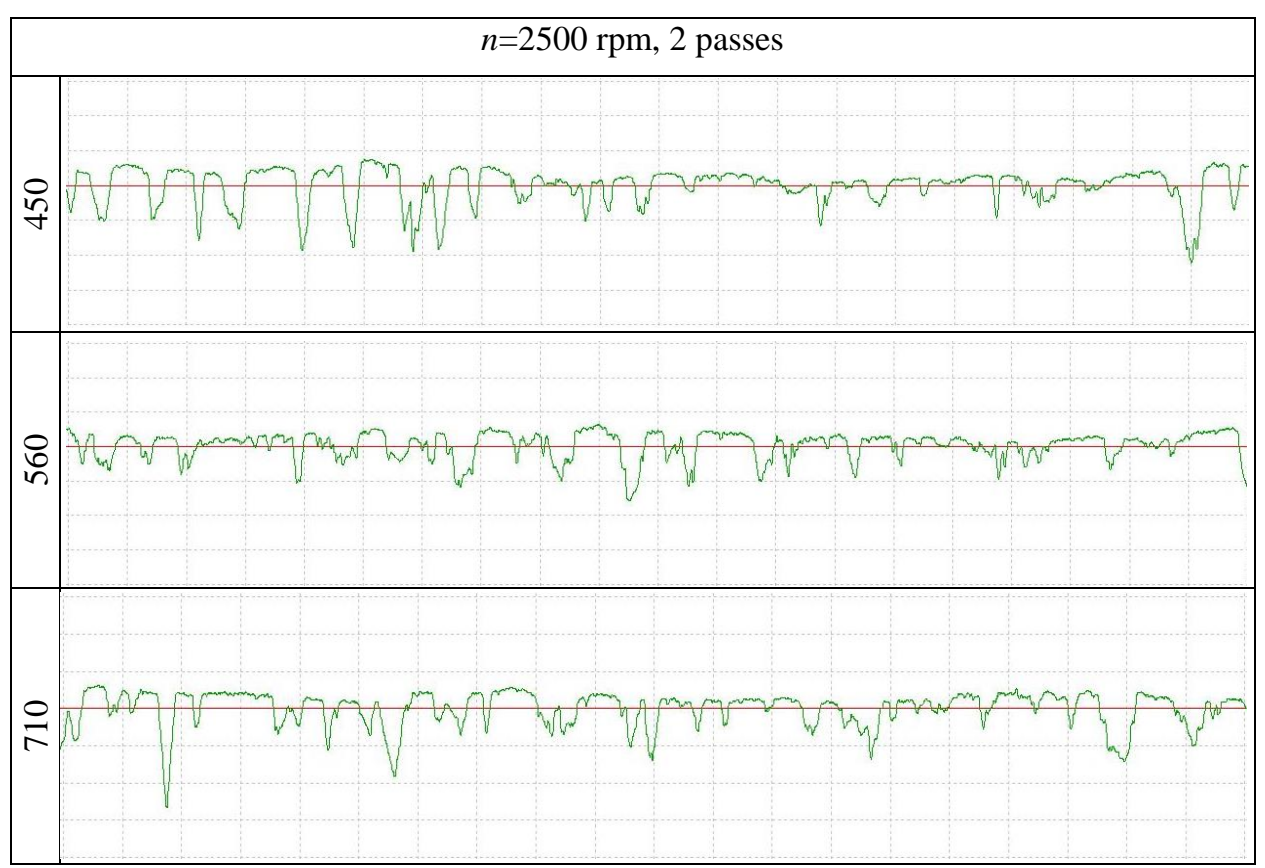

Fig. 4. Profiles of surfaces obtained by brushing at two tool passes, constant rotational speed $n=2500 \mathrm{rpm}$ and variable feed rates $v f=450,560$ and $710 \mathrm{~mm} / \mathrm{min}$ 
The next 3 profiles (Fig. 4) illustrate machining at the same rotational speeds and feed rates as previously ( $n=2500 \mathrm{rpm}, v f=450,560,710 \mathrm{~mm} / \mathrm{min})$, but at the number of tool passes increased to two. The general appearance of the profiles has not changed substantially in comparison with Fig. 3. Also in this case, single sharply tipped asperities occur at $v f=450 \mathrm{~mm} / \mathrm{min}$, and at $v f=560 \mathrm{~mm} / \mathrm{min}$ some levelling of valleys occurs. In the case of the profiles for the lowest feed rate, the most apparent difference is an increase in sharply tipped valleys at the expense of small asperities. There are more sharply tipped valleys than for the single tool pass.

The second profile and the third profile do not show any substantial changes in comparison with Fig. 3. It is mainly apparent that the second tool pass resulted in a more uniform distribution of asperities, to a large extent eliminating the areas in which no brushing effect had been previously visible. Moreover, the valleys standing out against the rest of the profile are no longer present in Fig. 4, whereby the profile is smoother.

Figure 5 shows the surfaces. It is clearly seen that the brushing process is a treatment that can modified only roughness vertices. Performing the 2D measurement, a characteristic flat-vertex structure was observed on the measured profiles. However, it was only by carrying out spatial measurements it was possible to conclude that there were no visible concentric traces relative to the midpoint in the axis of the rotating brush (which is a representation of the movement of the ceramic brush relative to the treated surface) Such modification made it possible to achieve a very advantageous isotropic structure with high load capacity, which is particularly advantageous in the further cooperation of the processed part with the counter element.

a)

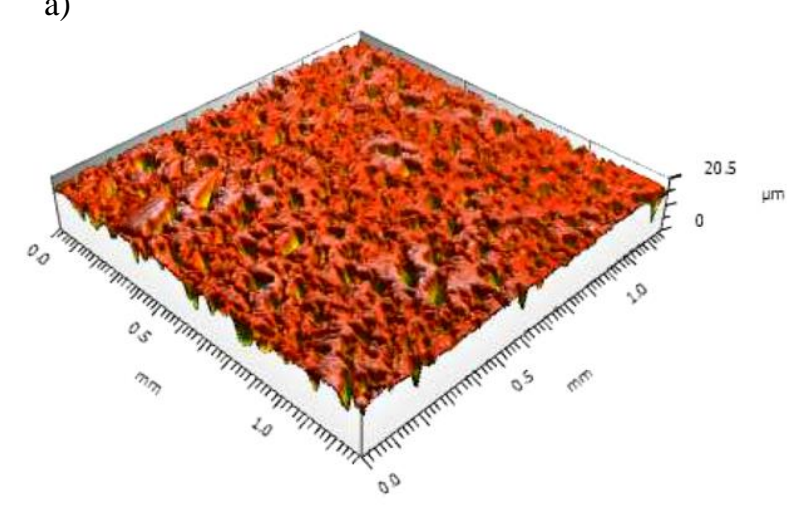

b)

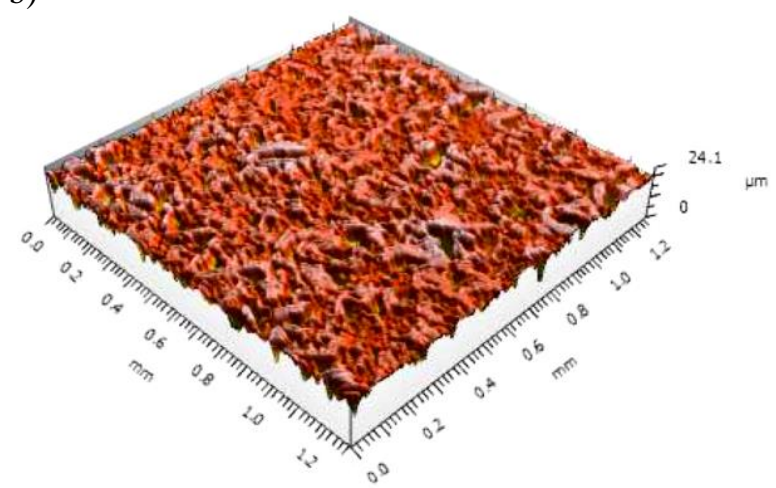

c)

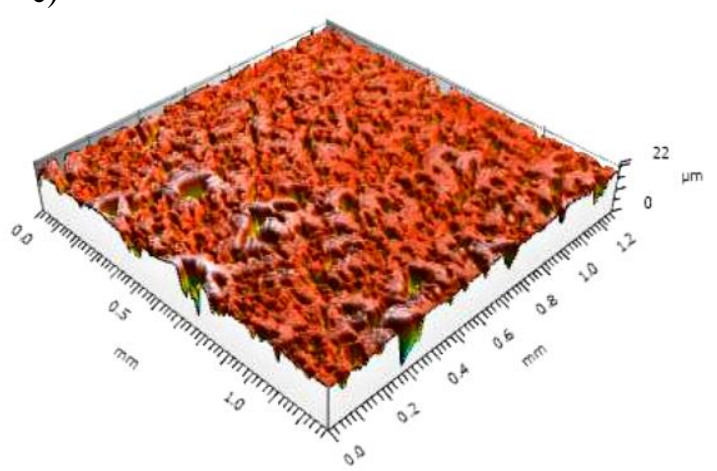

Fig. 5. Surfaces 3D obtained by brushing at two tool passes, constant rotational speed $n=2500 \mathrm{rpm}$ and variable feed rates $v f=450(\mathrm{a}), 560$ (b) and $710 \mathrm{~mm} / \mathrm{min}$ (c) 
Figure 5 shows the surfaces. It is clearly seen that the brushing process is a treatment that can modified only roughness vertices. Performing the 2D measurement, a characteristic flat-vertex structure was observed on the measured profiles. However, it was only by carrying out spatial measurements it was possible to conclude that there were no visible concentric traces relative to the midpoint in the axis of the rotating brush (which is a representation of the movement of the ceramic brush relative to the treated surface) Such modification made it possible to achieve a very advantageous isotropic structure with high load capacity, which is particularly advantageous in the further cooperation of the processed part with the counter element.

The values of fractal dimension $D$ and four height roughness parameters: $R a, R q, R s k$ and $R k u$ [14] were determined and compiled in table 4 . The values of the height parameters confirm the profile traces presented in Figs 3, 4. The results of 3D measurements of the fractal dimension and the parameters $S a, S q, S s k$ and $S k u$ are shown in Table 5. The smallest variation, not exceeding $1 \mu \mathrm{m}$, occurs for $R a$ and $R q$. The largest differences occur for profile slope $R k u$, which for different process parameters assumes values from 4.54 to 10.43. One can notice that for low rotational speeds $(n=2500 \mathrm{rpm})$ the second tool pass significantly lowers the value of $R k u$, flattening the outlines of the asperities. This is to some degree observed for the next speed $n=4000 \mathrm{rpm}$, but as the values of the machining parameters increase, this effect changes and the second tool pass begins to have a reverse effect, increasing parameter $R k u$.

Table 4. Brushing parameters and corresponding surface roughness parameters

\begin{tabular}{|c|c|c|c|c|c|c|c|c|c|c|}
\hline \multicolumn{6}{|c|}{ Parameter } & $\begin{array}{c}\text { Fractal } \\
\text { dimension }\end{array}$ & $R a$ & $R q$ & Rsk & $\begin{array}{c}R k u \\
{[-]}\end{array}$ \\
\hline \multirow{18}{*}{$\begin{array}{c}\text { Rotational } \\
\text { speed } n \\
{[\mathrm{rpm}]}\end{array}$} & \multirow{6}{*}{2500} & & \multirow{3}{*}{1} & \multirow{18}{*}{$\begin{array}{c}\text { Feed rate } v f \\
{[\mathrm{~mm} / \mathrm{min}]}\end{array}$} & 450 & 1.308 & 1.74 & 2.46 & 2.12 & 10.43 \\
\hline & & & & & 560 & 1.240 & 1.71 & 2.31 & 1.73 & 7.56 \\
\hline & & & & & 710 & 1.307 & 1.48 & 2.03 & 1.79 & 8.14 \\
\hline & & & & & 450 & 1.244 & 1.77 & 2.30 & 1.48 & 5.53 \\
\hline & & & 2 & & 560 & 1.245 & 2.06 & 2.71 & 1.42 & 6.24 \\
\hline & & & & & 710 & 1.254 & 1.89 & 2.43 & 1.34 & 5.26 \\
\hline & \multirow{6}{*}{4000} & \multirow{12}{*}{$\begin{array}{c}\text { Number } \\
\text { of } \\
\text { passes }\end{array}$} & \multirow{3}{*}{1} & & 450 & 1.228 & 1.55 & 2.13 & 1.97 & 10.31 \\
\hline & & & & & 560 & 1.231 & 1.70 & 2.23 & 1.37 & 5.70 \\
\hline & & & & & 710 & 1.267 & 1.59 & 2.12 & 1.59 & 6.47 \\
\hline & & & \multirow{3}{*}{2} & & 450 & 1.245 & 1.70 & 2.26 & 1.74 & 7.27 \\
\hline & & & & & 560 & 1.217 & 1.94 & 2.51 & 1.32 & 5.46 \\
\hline & & & & & 710 & 1.253 & 1.62 & 2.14 & 1.68 & 7.08 \\
\hline & \multirow{6}{*}{5500} & & \multirow{3}{*}{1} & & 450 & 1.267 & 1.49 & 1.98 & 1.64 & 5.75 \\
\hline & & & & & 560 & 1.212 & 2.00 & 2.54 & 1.17 & 4.54 \\
\hline & & & & & 710 & 1.234 & 1.98 & 2.63) & 1.52 & 6.68 \\
\hline & & & \multirow{3}{*}{2} & & 450 & 1.248 & 1.65 & 2.22 & 1.79 & 7.30 \\
\hline & & & & & 560 & 1.205 & 1.69 & 2.18 & 1.28 & 5.29 \\
\hline & & & & & 710 & 1.274 & 1.66 & 2.15 & 1.43 & 5.50 \\
\hline
\end{tabular}


Carrying out 3D measurements allows for obtaining parameters that are equivalent to those in the 2D measurement standards, but also those that can be calculated only for spatial roughness structures. For the comparative analysis of the results obtained for the profiles and for the surface fragments, the parameters that occur for both forms of roughness description were selected. The most frequently used parameters for a quantitative assessment are $R a(S a)$ and $R q(S q)$ however $R s k(S s k)$ and $R k u(S k u)$ for a qualitative assessment of the surface. It can be concluded that the altitude parameters for both measurement cases remain at a similar level, and that a slight decrease in their values for the 3D measurement is most likely caused by a greater number of collected measurement points, resulting in a greater average of the obtained results It can be concluded that, in the case of 3D measurement, a larger number of measuring points located a short distance from the average plane were scanned, which proves the high load-bearing capacity of the structure created (there's no large number of high vertices and deep depressions).

Table 5. Brushing parameters and corresponding surface roughness parameters 3D

\begin{tabular}{|c|c|c|c|c|c|c|c|c|c|c|}
\hline & & Paramet & & & & $\begin{array}{c}\text { Fractal } \\
\text { Dimension }\end{array}$ & $\begin{array}{c}S a \\
{[u m]}\end{array}$ & $\begin{array}{c}S q \\
{[u m]}\end{array}$ & Ssk [-] & $\begin{array}{c}S k u \\
{[-]}\end{array}$ \\
\hline & & & & & 450 & 2.65 & 1.61 & 2.12 & -2.56 & 12.89 \\
\hline & & & 1 & & 560 & 2.54 & 1.62 & 2.03 & -2.11 & 8.13 \\
\hline & & & & & 710 & 2.61 & 1.32 & 1.85 & -2.78 & 9.44 \\
\hline & 2500 & & & & 450 & 2.56 & 1.59 & 1.98 & -2.11 & 6.12 \\
\hline & & & 2 & & 560 & 2.63 & 1.87 & 2.43 & -2.58 & 8.14 \\
\hline & & & & & 710 & 2.59 & 1.71 & 2.22 & -2.51 & 7.11 \\
\hline & & & & & 450 & 2.63 & 1.44 & 1.87 & -2.56 & 12.75 \\
\hline & & & 1 & & 560 & 2.51 & 1.54 & 2.03 & -2.09 & 7.36 \\
\hline Rotational & & Number & 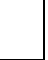 & Feed rate $v f$ & 710 & 2.57 & 1.46 & 1.91 & -2.34 & 7.99 \\
\hline $\begin{array}{l}\text { speed } n \\
{[\mathrm{rpm}]}\end{array}$ & 4000 & $\begin{array}{c}\text { of } \\
\text { passes }\end{array}$ & & {$[\mathrm{mm} / \mathrm{min}]$} & 450 & 2.51 & 1.52 & 1.95 & -2.73 & 8.45 \\
\hline & & & 2 & & 560 & 2.49 & 1.76 & 2.17 & -2.41 & 7.21 \\
\hline & & & & & 710 & 2.54 & 1.47 & 1.83 & -2.69 & 8.52 \\
\hline & & & & & 450 & 2.48 & 1.39 & 1.65 & -2.61 & 6.79 \\
\hline & & & 1 & & 560 & 2.41 & 1.81 & 2.17 & -2.01 & 5.9 \\
\hline & 5 & & & & 710 & 2.41 & 1.82 & 2.26 & -2.31 & 8.15 \\
\hline & 5500 & & & & 450 & 2.53 & 1.56 & 1.95 & -2.11 & 8.62 \\
\hline & & & 2 & & 560 & 2.51 & 1.54 & 1.91 & -2.28 & 7.19 \\
\hline & & & & & 710 & 2.56 & 1.51 & 1.92 & -2.31 & 7.02 \\
\hline
\end{tabular}

Analysing the results of the 3D measurement, a significant decrease in the value of the skewness parameter measured with this method was found (in relation to the 2D measurements). This proves a more complete description of the nature of the measured surface and the transition from positive to negative values is the information that the flat vertices (visible on individual profiles, in spatial images, are fragments of plateau-structured fields, which occupy quite large areas of the assessed surface. The increase in the value 
of kurtosis measured with the 3D method may prove that the measurement of a single profile does not always allow for the correct determination of the depth of the grooves - for the flat-apical structure obtained during measurements (or the height of the vertices for pointed-apical structures). Spatial description of these elements gives a better chance of scanning the entire volume of vertices and valleys, and a better assessment of the nature of the surface under investigation.

The change in fractal dimension $D$ depending on the adopted machining parameters is shown in four bar charts - Figs 6 and 7. One can see that the highest $D$ values are connected with the extreme machining parameters: $n=2500 \mathrm{rpm}, v f=450$ and $710 \mathrm{~mm} / \mathrm{min}$. For constant rotational speed $n=4000 \mathrm{rpm}$ and constant feed rate $v f=560 \mathrm{~mm} / \mathrm{min}$ the fractal dimension assumes low values, differing only slightly between one and two tool passes. The largest differences in 2D fractal dimension depending on the number of passes are observed for the one- and two-pass tests in which $n=2500 \mathrm{rpm}$ and $v f=450 \mathrm{~mm} / \mathrm{min}$ were used. Such large differences in the fractal dimension for the surface after 1 pass and 2 passes of the brush were not noticed in the case of 3D surfaces. It can be noticed that the fractal dimension calculated for the surface takes values greater (within the possible range) than the dimension calculated for the profile. It is related to the increase the accuracy of mapping the actual geometric structure of the surface in 3D measurement.
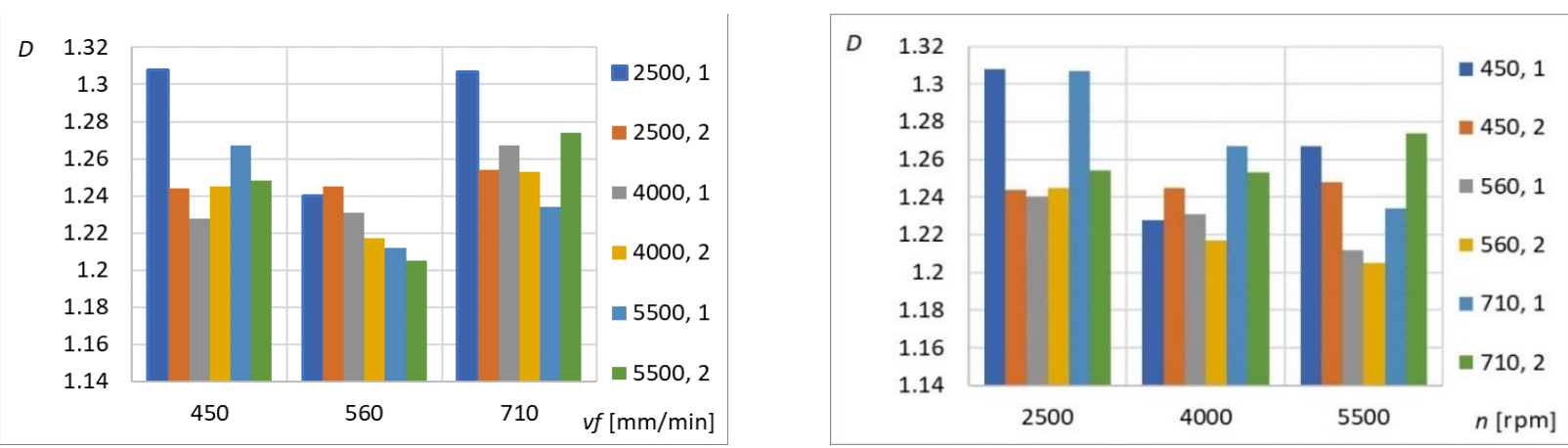

Fig. 6. Changes in fractal dimension $D(n)$ for surface profiles at $v f=$ const and $D(v f)$ at $n=$ const
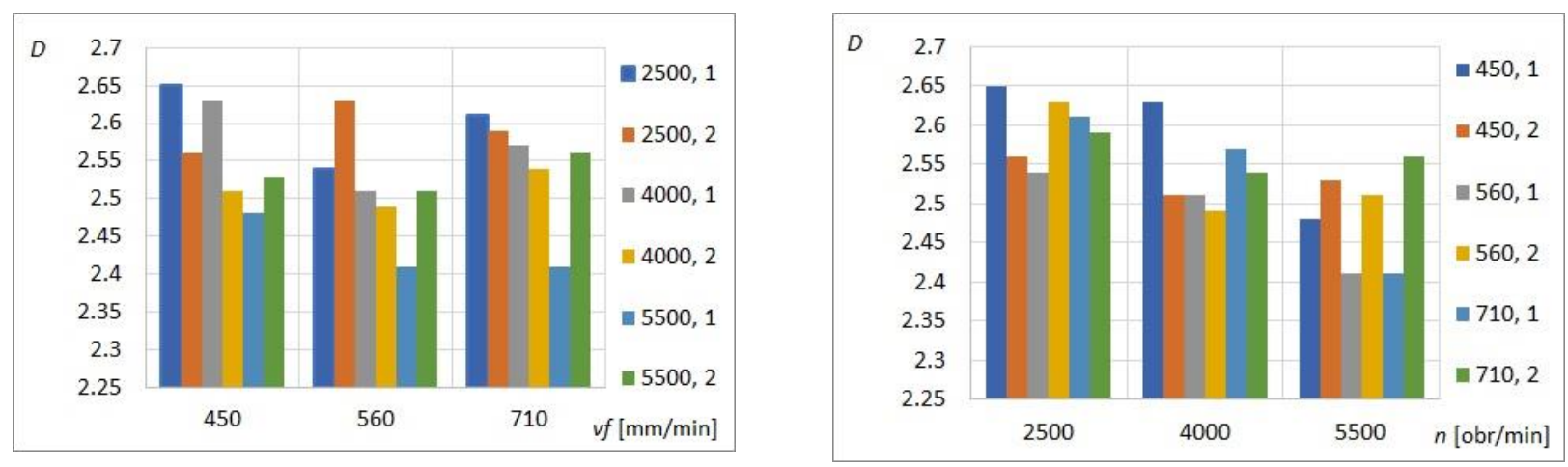

Fig. 7. Changes in fractal dimension $D(n)$ for surfaces 3D at $v f=$ const and $D(v f)$ at $n=$ const

On the basis of the fractal dimension values contained in Tables 4, 5 and the corresponding values of parameters $R a$ and $S a$ the correlation coefficients between parameters $R a$, 
$S a$ and parameter $D$ were determined for the successive rotational speeds $n$ and feed rates $v f$. The results are compiled in Tables 6 and 7.

For the constant feed rate values the results were highly correlated, whereas in the case of rotational speed the correlation coefficient ranged widely. The weakest correlation was observed for the lowest rotational speed of $2500 \mathrm{rpm}$ and the highest for $v f=560 \mathrm{~mm} / \mathrm{min}$. A strong correlation occurred for most of the results, which indicates that the fractal dimension could be an alternative to $R a$ or $S a$.

Table 6. Coefficients of correlation between fractal dimension $D$ and roughness $R a$ for constant rotational speeds $n$ and constant feed rates $v f$

\begin{tabular}{|c|c|c|c|c|}
\hline $\begin{array}{l}\text { Number of } \\
\text { passes }\end{array}$ & $\begin{array}{c}\text { Rotational speed } \\
n[\mathrm{rpm}]\end{array}$ & $\begin{array}{l}\text { Correlation } \\
\text { coefficient }\end{array}$ & $\begin{array}{c}\text { Feed rate } v f \\
{[\mathrm{~mm} / \mathrm{min}]}\end{array}$ & $\begin{array}{l}\text { Correlation } \\
\text { coefficient }\end{array}$ \\
\hline 1 & \multirow{2}{*}{2500} & -0.39 & \multirow{2}{*}{450} & 0.74 \\
\hline 2 & & -0.01 & & -0.95 \\
\hline 1 & \multirow{2}{*}{4000} & -0.17 & \multirow{2}{*}{560} & -0.94 \\
\hline 2 & & -1.00 & & 0.92 \\
\hline 1 & \multirow{2}{*}{5500} & -0.93 & \multirow{2}{*}{710} & -0.93 \\
\hline 2 & & -0.82 & & -0.35 \\
\hline
\end{tabular}

Table 7. Coefficients of correlation between fractal dimension $D$ and roughness $S a$ for constant rotational speeds $n$ and constant feed rates $v f$

\begin{tabular}{|c|c|c|c|c|}
\hline $\begin{array}{c}\text { Number of } \\
\text { passes }\end{array}$ & $\begin{array}{c}\text { Rotational speed } \\
n[\mathrm{rpm}]\end{array}$ & $\begin{array}{l}\text { Correlation } \\
\text { coefficient }\end{array}$ & $\begin{array}{c}\text { Feed rate } v f \\
{[\mathrm{~mm} / \mathrm{min}]}\end{array}$ & $\begin{array}{l}\text { Correlation } \\
\text { coefficient }\end{array}$ \\
\hline 1 & \multirow{2}{*}{2500} & 0.18 & \multirow{2}{*}{450} & 0.75 \\
\hline 2 & & 1.00 & & 0.98 \\
\hline 1 & \multirow{2}{*}{4000} & -0.94 & \multirow{2}{*}{560} & -0.87 \\
\hline 2 & & -0.89 & & 0.66 \\
\hline 1 & \multirow{2}{*}{5500} & -1.00 & \multirow{2}{*}{710} & -1.00 \\
\hline 2 & & -0.68 & & 0.97 \\
\hline
\end{tabular}
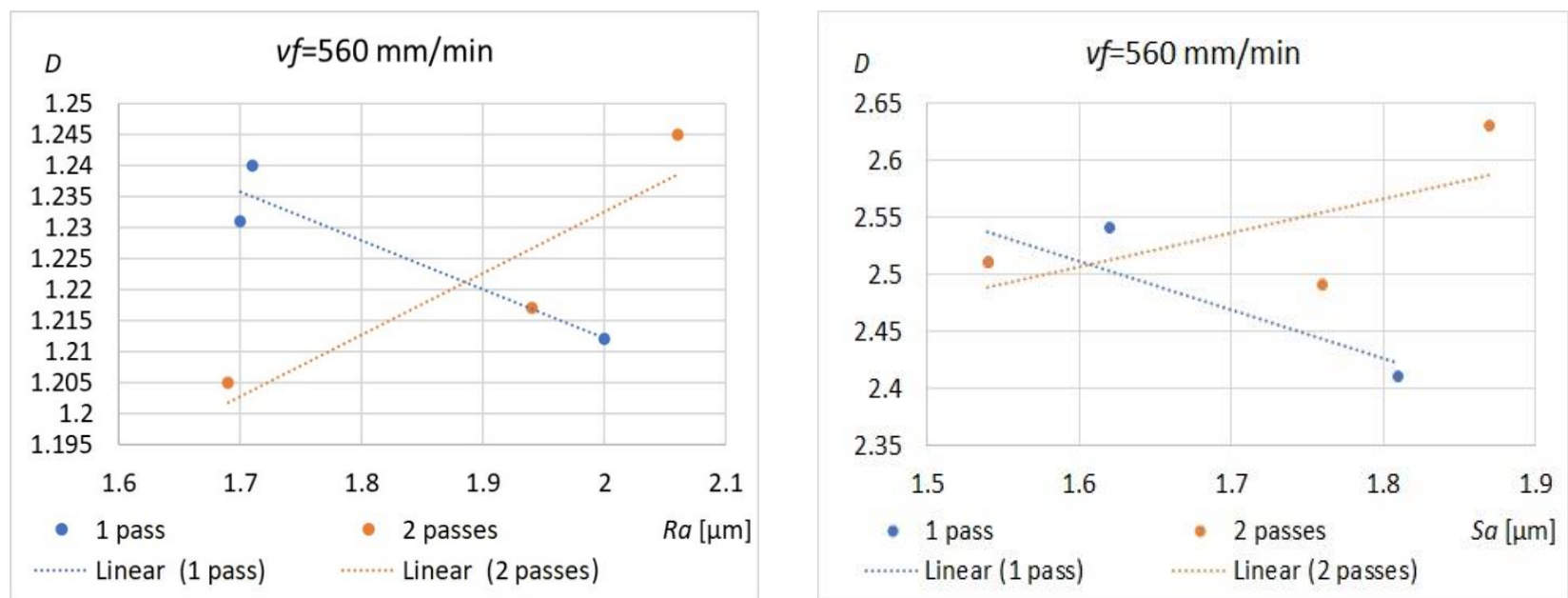

Fig. 8. Fractal dimension $D$ versus parameter $R a$ and $S a$ at constant tool feed rate $v f=560 \mathrm{~mm} / \mathrm{min}$ 
Figure 8 shows a dot diagram for the case when a very high correlation occurred for one and two tool passes at $v f=560 \mathrm{~mm} / \mathrm{min}$. The trend lines' slope and closeness to the determined points corroborate the high correlation between $R a, S a$ and the fractal dimension.

The correlation coefficient values for parameter $R q$ and $S q$ are presented in Tables 8 and 9. The results are similar to the ones obtained for parameters $R a$ and $S a$. Again the weakest correlation was noted for constant rotational speed $n=2500 \mathrm{rpm}$. At the constant feed rate the correlation coefficient values and their distribution were similar to the ones obtained for $R a$ and $S a$. The similarity is probably due to the similar function of the two parameters and the similar way of determining them $-R q$ and $S q$ is calculated as the quadratic mean of the profile ordinates (within the roughness sampling length) [15]. The similarity between parameters $R a, S a$ and $R q, S q$ can also be noticed in the dot diagram showing the $D(R q)$ and $D(S q)$ relation. The distribution of the points and the slope for the two passes are very similar to the ones shown in Fig. 9.

Table 8. Coefficients of correlation between fractal dimension $D$ and roughness parameter $R q$ for constant rotational speeds $\mathrm{n}$ and constant feed rates $v f$

\begin{tabular}{|c|c|c|c|c|}
\hline $\begin{array}{c}\text { Number of } \\
\text { passes }\end{array}$ & $\begin{array}{c}\text { Rotational speed } \\
n[\mathrm{rpm}]\end{array}$ & $\begin{array}{l}\text { Correlation } \\
\text { coefficient }\end{array}$ & $\begin{array}{c}\text { Feed rate } v f \\
{[\mathrm{~mm} / \mathrm{min}]}\end{array}$ & $\begin{array}{l}\text { Correlation } \\
\text { coefficient }\end{array}$ \\
\hline 1 & \multirow{2}{*}{2500} & -0.16 & \multirow{2}{*}{450} & 0.68 \\
\hline 2 & & -0.12 & & -0.97 \\
\hline 1 & \multirow{2}{*}{4000} & -0.50 & \multirow{2}{*}{560} & -0.85 \\
\hline 2 & & -0.99 & & 0.94 \\
\hline 1 & \multirow{2}{*}{5500} & -0.86 & \multirow{2}{*}{710} & -0.91 \\
\hline 2 & & -0.25 & & -0.44 \\
\hline
\end{tabular}

Table 9. Coefficients of correlation between fractal dimension $D$ and roughness parameter $S q$ for constant rotational speeds $\mathrm{n}$ and constant feed rates $v f$

\begin{tabular}{|c|c|c|c|c|}
\hline $\begin{array}{c}\text { Number of } \\
\text { passes }\end{array}$ & $\begin{array}{l}\text { Rotational speed } \\
n[\mathrm{rpm}]\end{array}$ & $\begin{array}{l}\text { Correlation } \\
\text { coefficient }\end{array}$ & $\begin{array}{c}\text { Feed rate } v f \\
{[\mathrm{~mm} / \mathrm{min}]}\end{array}$ & $\begin{array}{l}\text { Correlation } \\
\text { coefficient }\end{array}$ \\
\hline 1 & \multirow{2}{*}{2500} & -0.18 & \multirow{2}{*}{450} & 0.90 \\
\hline 2 & & 0.99 & & 0.92 \\
\hline 1 & \multirow{2}{*}{4000} & -0.96 & \multirow{2}{*}{560} & -0.98 \\
\hline 2 & & -0.96 & & 0.79 \\
\hline 1 & \multirow{2}{*}{5500} & -0.99 & \multirow{2}{*}{710} & -1.00 \\
\hline 2 & & 0.13 & & 0.98 \\
\hline
\end{tabular}

The observed good correlation between the fractal dimension $D$ and the $R a$ and $S a$ parameters as well as $R q$ and $S q$ can be, for higher rotational speed $n$ of the brush, explained by the fact that this tool, with the increase of the spin speed, additionally stiffens and more "aggressively" maps the trace on the machined surface, left by single ceramic fibers. Such a stronger interaction of fibers, on the surface with initially relatively small machining 
depths, will generate additional, deep grooves on the surface, which will reduce the fractal dimension while increasing the average height of peaks and depressions equally intensively, which will result in an increase in height parameters calculated as arithmetic means, or the square deviation of the profile (surface) from the mean line (plane).

In the case of variable feed rate, quite a lot of ambiguity can be found. For measurements of a single 2D profile as well as measurements of 3D spatial structures, it can be concluded, for the first brush pass, that an increase in the feed rate causes a shift from a high positive correlation to a high negative one. This may be due to greater deflection of the brush fibers due to the feed component of the cutting force. The deflection will be greater, the higher the feed rate. Fibers are working with greater deflection will slide more on the surface and process it without generating additional "noise", which may cause an increase in the fractal dimension. In the second, smoothing passage of the brush, the tool, working on the surface with lower roughness, encounters a lower cutting resistance in the direction opposite to the feed direction, and single fibers working on the pre-smoothed surface after the first brushing are able to generate new deep marks.
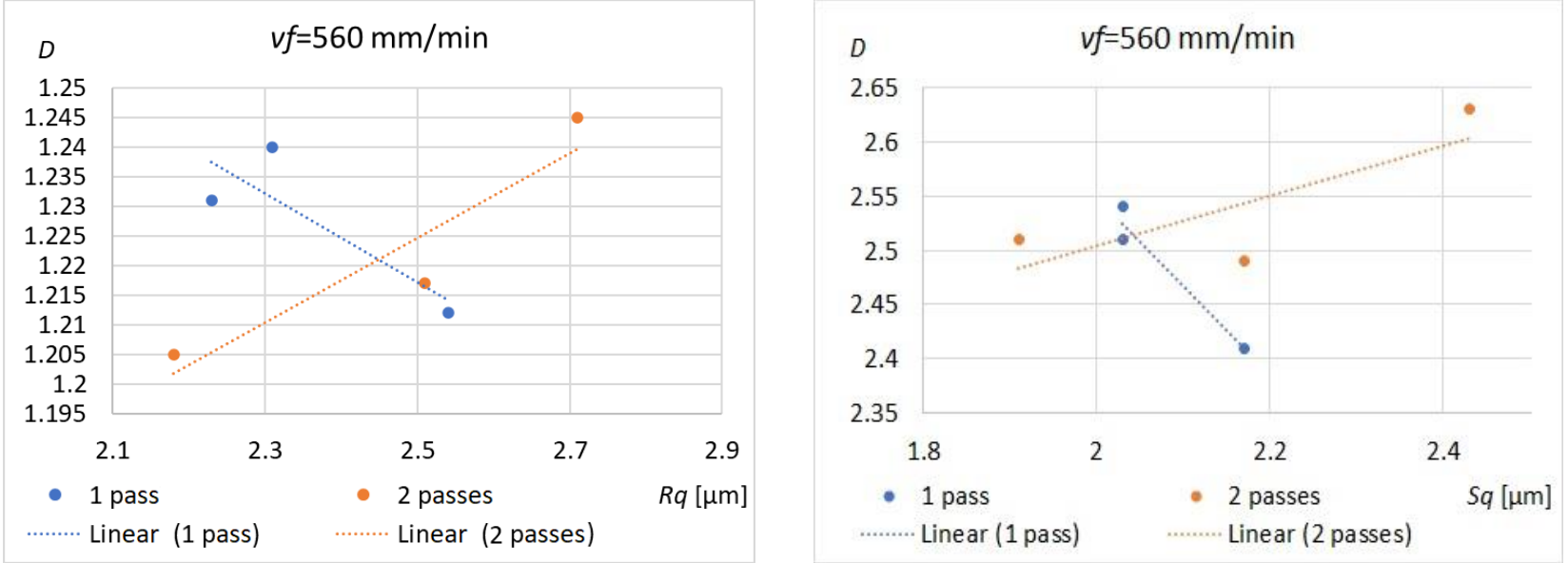

Fig. 9. Fractal dimension $D$ versus parameters $R q$ and $S q$ at constant tool feed rate $v f=560 \mathrm{~mm} / \mathrm{min}$

Tables 10 and 11 shows the coefficients of correlation between fractal dimension $D$ and roughness parameters $R s k$, Ssk at the adopted constant rotational speeds $n$ and constant feed rates $v f$. Similarly as for the parameters analysed above, also in this case the correlation ranges widely from a weak correlation (-0.24) to a very strong correlation (1.00).

$R s k$ and $S s k$ are a profile or surface asymmetry coefficients expressing the skewness of the distribution of ordinates. They have an averaging character and can assume positive values for structures with numerous peaks and negative values for surfaces with predominant valleys. The further this parameters are distant from zero, the more nonuniform the distribution of the material. Rsk and $S s k$ are calculated as the ratio of the mean value of cubed profile ordinates $Z(x)$ to the third power of parameter $R q$ or $S q$ (within the roughness sampling length) [15]. Hence, similarly as in the case of the previous coefficients, there is a noticeable scatter of the correlation coefficient, but it is smaller than for $R a, S a$ and $R q, S q$ and the minimal values are higher, which is a direct indication that the fractal dimension will perform better as a substitute for $R s k$ and $S s k$. It can be expected that 
the correlation of changes in the fractal dimension with changes in the assessed roughness parameters will be greater due to the greater number of scanned measuring points and the extension of the measurement to the third axis, even in the case of isotropic surfaces, which we deal with in the examined case.

Table 10. Coefficients of correlation between fractal dimension $D$ and roughness coefficient $R s k$ for constant rotational speeds $n$ and constant feed rates $v f$

\begin{tabular}{|c|c|c|c|c|}
\hline $\begin{array}{l}\text { Number } \\
\text { of passes }\end{array}$ & $\begin{array}{c}\text { Rotational } \\
\text { speed } n[\mathrm{rpm}]\end{array}$ & $\begin{array}{l}\text { Correlation } \\
\text { coefficient }\end{array}$ & $\begin{array}{c}\text { Feed rate } v f \\
{[\mathrm{~mm} / \mathrm{min}]}\end{array}$ & $\begin{array}{c}\text { Correlation } \\
\text { coefficient }\end{array}$ \\
\hline 1 & \multirow{2}{*}{2500} & 0.63 & \multirow{2}{*}{450} & 0.32 \\
\hline 2 & & -0.94 & & 0.83 \\
\hline 1 & \multirow{2}{*}{4000} & -0.24 & \multirow{2}{*}{560} & 0.93 \\
\hline 2 & & 0.94 & & 1.00 \\
\hline 1 & \multirow{2}{*}{5500} & 0.93 & \multirow{2}{*}{710} & 0.98 \\
\hline 2 & & 0.42 & & -0.29 \\
\hline
\end{tabular}

Table 11. Coefficients of correlation between fractal dimension $D$ and roughness coefficient $S s k$ for constant rotational speeds $n$ and constant feed rates $v f$

\begin{tabular}{|c|c|c|c|c|}
\hline $\begin{array}{l}\text { Number } \\
\text { of passes }\end{array}$ & $\begin{array}{c}\text { Rotational } \\
\text { speed } n[\mathrm{rpm}]\end{array}$ & $\begin{array}{l}\text { Correlation } \\
\text { coefficient }\end{array}$ & $\begin{array}{c}\text { Feed rate } v f \\
{[\mathrm{~mm} / \mathrm{min}]}\end{array}$ & $\begin{array}{l}\text { Correlation } \\
\text { coefficient }\end{array}$ \\
\hline 1 & \multirow{2}{*}{2500} & 0.77 & \multirow{2}{*}{450} & 0.99 \\
\hline 2 & & -0.89 & & 0.80 \\
\hline 1 & \multirow{2}{*}{4000} & -1.00 & \multirow{2}{*}{560} & 0.81 \\
\hline 2 & & -0.73 & & -1.00 \\
\hline 1 & \multirow{2}{*}{5500} & -0.87 & \multirow{2}{*}{710} & -0.70 \\
\hline 2 & & -0.25 & & 0.37 \\
\hline
\end{tabular}
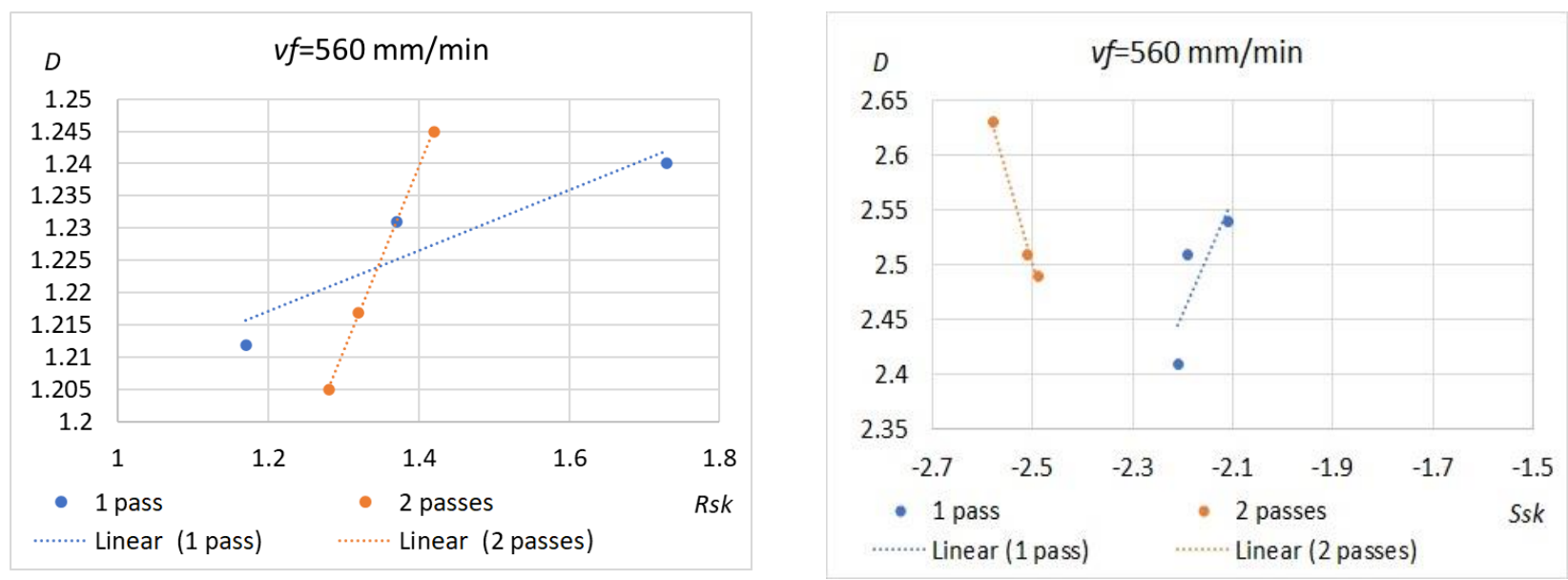

Fig. 10. Fractal dimension $D$ versus parameters $R s k$ and $S s k$ at constant tool feed rate $v f=560 \mathrm{~mm} / \mathrm{min}$

Again the best correlation occurred at $v f=560 \mathrm{~mm} / \mathrm{min}$. As Fig. 10 shows, in this case a full correlation occurs for two passes, as reflected by the fact that the trend line passes through all the determined points. 
The next analysed parameters are profile and surface slope coefficient $R k u$ and $S k u$. Tables 12 and 14 shows the level of this parameters correlation with fractal dimension $D$ for constant rotational speeds $n$ and constant feed rates $v f$. Despite the large scatter $(0.04 \div 1.00)$ of the correlation coefficient, in most cases the profile slope-fractal dimension correlation is high, indicating that fractal dimension $D$ can be alternatively applied to the considered parameter.

Table 12. Coefficients of correlation between fractal dimension $D$ and roughness parameter $R k u$ for constant rotational speeds $n$ and constant feed rates $v f$

\begin{tabular}{|c|c|c|c|c|}
\hline $\begin{array}{l}\text { Number } \\
\text { of passes }\end{array}$ & $\begin{array}{c}\text { Rotational speed } \\
n[\mathrm{rpm}]\end{array}$ & $\begin{array}{l}\text { Correlation } \\
\text { coefficient }\end{array}$ & $\begin{array}{l}\text { Feed rate } v f \\
{[\mathrm{~mm} / \mathrm{min}]}\end{array}$ & $\begin{array}{l}\text { Correlation } \\
\text { coefficient }\end{array}$ \\
\hline 1 & \multirow{2}{*}{2500} & 0.67 & \multirow{2}{*}{450} & 0.04 \\
\hline 2 & & -0.65 & & 0.75 \\
\hline 1 & \multirow{2}{*}{4000} & -0.44 & \multirow{2}{*}{560} & 0.94 \\
\hline 2 & & 0.95 & & 0.99 \\
\hline 1 & \multirow{2}{*}{5500} & 0.47 & \multirow{2}{*}{710} & 0.83 \\
\hline 2 & & 0.24 & & -0.42 \\
\hline
\end{tabular}

Table 13. Coefficients of correlation between fractal dimension $D$ and roughness parameter $S k u$ for constant rotational speeds $n$ and constant feed rates $v f$

\begin{tabular}{|c|c|c|c|c|}
\hline $\begin{array}{l}\text { Number } \\
\text { of passes }\end{array}$ & $\begin{array}{l}\text { Rotational speed } \\
n[\mathrm{rpm}]\end{array}$ & $\begin{array}{l}\text { Correlation } \\
\text { coefficient }\end{array}$ & $\begin{array}{c}\text { Feed rate } v f \\
{[\mathrm{~mm} / \mathrm{min}]}\end{array}$ & $\begin{array}{l}\text { Correlation } \\
\text { coefficient }\end{array}$ \\
\hline 1 & \multirow{2}{*}{2500} & -0.92 & \multirow{2}{*}{450} & 1.00 \\
\hline 2 & & 1.00 & & -0.89 \\
\hline 1 & \multirow{2}{*}{4000} & 0.91 & \multirow{2}{*}{560} & 0.99 \\
\hline 2 & & 0.83 & & 0.99 \\
\hline 1 & \multirow{2}{*}{5500} & -0.12 & \multirow{2}{*}{710} & 0.58 \\
\hline 2 & & -0.21 & & -0.77 \\
\hline
\end{tabular}

$R k u$ and $S k u$ are a measure of the amplitude density curve's acuteness, also referred to as a flattening coefficient [15]. They have a value limit of 3. Below this limit the asperities are longer and the peaks are more filled with the material, while above this limit they become sharper and shorter. Thus, similarly as the fractal dimension, parameters $R k u$ and $S k u$ indicate the degree of surface irregularity.

The results obtained for the flattening coefficient are very similar to the ones obtained for $R s k$ and $S s k$ as regards both the character of the correlation (mostly positive) and the particular values. Figure 11 shows the points for $v f=560 \mathrm{~mm} / \mathrm{min}$. A similar distribution of values as in the case of $R a$ and $R q$ occurred for $R s k$ and $R k u$ and the obtained trend lines were similar to the ones shown in Fig. 11.

Spatial description of these peaks and depressions on the tested surface, as mentioned earlier, gives a better chance to scan the entire volume of peaks and valleys and to better assess the nature of the tested surface. This concerns both the assessment of statistical parameters (skewness and kurtosis) and the fractal dimension. The parameter D calculated for 2D and 3D measurements shows an increase for tenths and hundredths of the measured 
values. It proves that only the spatial analysis allows for a more complete assessment of the surface and the capture of additional disturbances on the elements it consists of (such as the sides of vertices and depressions).
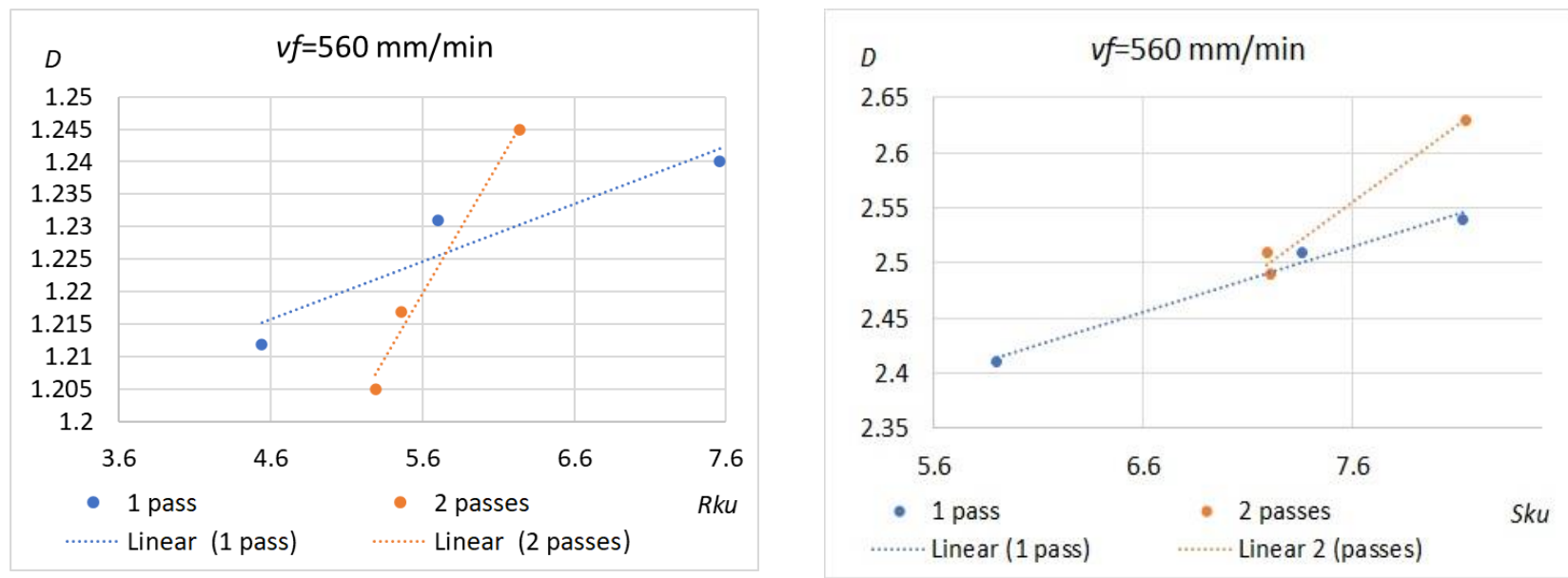

Fig. 11. Fractal dimension $D$ versus parameters $R k u$ and $S k u$ at constant tool feed rate $v f=560 \mathrm{~mm} / \mathrm{min}$

Such additional disturbance on the sides of the cavities is most likely due to the nature of the abrasive tool, the multifilament ceramic brush, the application of which on the surface (despite the stiffening sleeves) generates additional "notching" associated with imperfect tool rigidity.

\section{CONCLUSION}

Obtained results confirmed that the fractal dimension can be used as a supplement to the description of the roughness of an isotropic surface with a flat-vertex structure.

The fractal dimension calculated using the box method correlates particularly strongly with the statistical parameters $R s k(S s k)$ and $R k u(S k u)$. All these parameters carry information about irregularities occurring in the roughness profile or individual irregularities occurring on the assessed surface. Skewness, kurtosis and fractal dimensions are all tools for assessing the quality of the obtained surface structure, but they describe deviations at different levels of their size. Statistical parameters detect changes at the level recognized by the standard as roughness, while the fractal best describes the roughness noise. Therefore, it can be considered as a complementary tool, which extends the description of the geometrical features of the surface layer.

Due to the fact that there is no universal parameter that could serve as a single parameter for a relatively complete description of the surface, - the fractal dimension seems to be an indicator that complements the classic roughness parameters. In the analysed case, in which tool was a ceramic abrasive brush, plateau structures were obtained with a roughness corresponding to medium-fine grinding. In the case of shaping and finishing treatments, the fractal dimension can be an interesting alternative to the statistical moment 
of the fourth order (kurtosis). This is related, as mentioned earlier, to the scope of application of both these parameters. Kurtosis reflects the condition of the features at the level of roughness, the fractal dimension at the level of noise generated on individual components of the examined structures.

It is also worth emphasizing the advantages of brushing as one of the less frequently used methods of machining. After its application, it is possible to obtain surfaces with high load-bearing capacity and a roughness corresponding to moderate abrasive machining. The process is carried out at low processing temperatures, so it can be assumed that the surface layer will be free from the influence of heat, and thus the tensile stresses arising in accordance with the so-called hot model of stress generation. All these advantages make brushing an interesting alternative to other abrasive treatments, especially grinding.

\section{REFERENCES}

[1] WIECZOROWSKI M., 2009, The Use of Topographic Analysis in the Measurement of Surface Roughness, Wydawnictwo Politechniki Poznańskiej, (in Polish).

[2] GAWLIK J., MAGDZIARCZYK W., WOJNAR L., 2011, Fractal Analysis of the Geometric Structure of the Surface, Komputerowo Zintegrowane Zarządzanie. T. 2 ,Ofic. Wydaw. Polskiego Towarzystwa Zarządzania Produkcją, 382-396, (in Polish).

[3] KUDREWICZ J., 2015, Fractals and chaos, Warszawa: Wydawnictwo WNT, (in Polish).

[4] PEITGEN H.O., JURGENS H., SAUPE D., 1995, Limits of Chaos: Fractals, Part 1, Wydawnictwo Naukowe PWN, (in Polish).

[5] ZHANG X., ZHENG G., CHENG X., LI Y., LI L., LIU H., 2020, 2D Fractal Analysis of the Cutting Force and Surface Profile in Turning of Iron-Based Superalloy, Measurement, 151, 107125.

[6] GRZESIK W., BROL S., 2009, Wavelet and Fractal Approach to Surface Roughness Characterization after Finish Turning of Different Workpiece Materials, Journal of Materials Processing Technology, 209, $2522-2531$.

[7] KANG M.C., KIM J.S., KIM K.H., 2005, Fractal Dimension Analysis of Machined Surface Depending on Coated Tool Wear, Surface \& Coatings Technology 193, 259- 265.

[8] PAPANIKOLAOU M., SALONITIS K., 2019, Fractal Roughness Effects on Nanoscale Grinding, Applied Surface Science, 467-468, 309-319.

[9] ZHAO B., LI P., ZHAO C., WANG X., 2020, Fractal Characterization of Surface Microtexture of Ti6Al4V Subjected to Ultrasonic Vibration Assisted Milling, Ultrasonics, 102, 106052.

[10] WEI S., ZHAOA H., JING J., 2015, Investigation on Three-Dimensional Surface Roughness Evaluation of Engineering Ceramic for Rotary Ultrasonic Grinding Machining, Applied Surface Science, 357, $139-146$.

[11] LI G., ZHANG K., GONG J., JIN X., 2019, Calculation Method for Fractal Characteristics of Machining Topography Surface Based of Wavelet Transform, Procedia CIRP, 79, 500-504.

[12] EL-SONBATY I.A., KHASHABA U.A., SELMY A.I., ALI A.I., 2008, Prediction of Surface Roughness Profiles for Milled Surfaces Using an Artificial Neural Network and Fractal Geometry Approach, Journal of Materials Processing Technology, 200, 271-278.

[13] SAŁACIŃSKI T., PAJĄK P., 2015, Ceramic Tools for Surface Finish Deburring and Polishing Operations, Mechanik, 10, 762-765, (in Polish).

[14] PN-EN ISO 4287-1999, Product Geometry Specifications. Geometric Structure of the Surface: Profile MethodTerms, Definitions and Parameters of the Structure, Polski Komitet_Normalizacyjny, (in Polish).

[15] ADAMCZAK S., 2008, Geometric Measurements of the Surface: Shape Outlines, Wavy and Roughness, Warszawa: Wydawnictwa Naukowo-Techniczne, (in Polish). 